\title{
SYSTEMATIC THINKING
}

Dear Reader,

In 2018, there are likely to be around 1.5 billion cars on our roads throughout the world - twice as many as only a decade ago. For that reason, carbon emissions resulting from our energy requirements and energy mix will become an increasingly important topic. And it is even more of an issue when one considers that, in recent years, $\mathrm{CO}_{2}$ emissions have been reduced in all sectors except in the field of road traffic. It is true that the industry has made considerable efforts, particularly in in-engine emissions reduction and lightweight design. It has also made progress in powertrain engineering: small, highly efficient engines have long since become the norm, and new hybrid and electric drive systems are about to be launched. However, it will be 2030 before the latter make up any significant proportion of the overall mileage driven.

That means that internal combustion engines will still play a vital role, at least over the next 20 years. But there is still a great dependency on fossil fuels. What we need is a systematic approach that considers the development of the entire energy chain from the well to the wheel. Biofuels are not necessarily the solution. Their carbon emissions over the whole production chain must be taken into account.

One solution might be found in alternative fuels from other regenerative sources. The increasing proportion of regenerative energy in the power supply network alone does not make any relevant contribution to climate protection in road traffic.
If electric energy is used for vehicles, additional capacity will be required for regenerative electricity. In future, it might be possible to produce gaseous or liquid fuels synthetically from regenerative electric energy. This approach is still in its early stages and implementation is still a long way off. Nevertheless, the use of these kinds of fuels is particularly interesting and forward-looking because they offer a real alternative.

Only in this way - with a consistently systematic approach towards both drive systems and fuels - will it really be possible to achieve important climate targets.

Best regards,

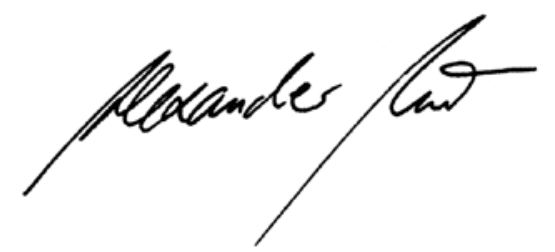

DR. ALEXANDER HEINTZEL, Editor in Chief Wiesbaden, 7 February 2013

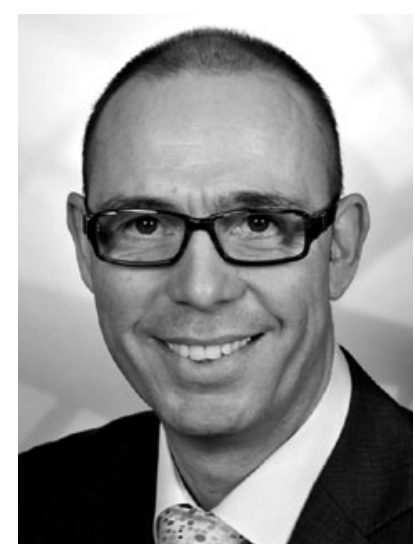

